\title{
Hydrogen bond in imidazolium based protic and aprotic ionic liquids
}

Hikari Watanabe ${ }^{\text {a }}$, Hiroyuki Doi ${ }^{\text {a }}$, Soshi Saito ${ }^{a}$, Masaru Matsugami ${ }^{\text {b }}$, Kenta Fujii ${ }^{\text {c }}$, Ryo Kanzaki $^{\mathrm{d}}$, Yasuo Kameda ${ }^{\mathrm{e}}$, Yasuhiro Umebayashi ${ }^{\mathrm{a}}{ }^{*}$

${ }^{a}$ Graduate School of Science and Engineering, Niigata University, Niigata 950-2181, Japan,

${ }^{b}$ Faculty of Liberal Studies, National Institute of Technology, Kumamoto College, 2659-2 Suya, Koshi, Kumamoto 861-1102, Japan ${ }^{\mathrm{c}}$ Graduate School of Science and Engineering, Yamaguchi University, Yamaguchi 755-8611, Japan

${ }^{\mathrm{d}}$ Graduate School of Science and Engineering, Kagoshima University, Kagoshima 890-0065, Japan

e Department of Material and Biological Chemistry, Faculty of Science, Yamagata University, Yamagata 990-8560, Japan

*Corresponding author: Yasuhiro Umebayashi, yumescc@chem.sc.niigata-u.ac.jp

\begin{abstract}
Liquid structure of bis-(trifluoromethanesulfonyl)amide TFSA $^{-}$based protic and aprotic ionic liquids composed of imidazolium $\left[\mathrm{h}_{2} \mathrm{Im}^{+}\right], N$-methylimidazolium $\left[\mathrm{C}_{1} \mathrm{hIm}^{+}\right]$ and $N, N^{\prime}$-dimethylimidazolium $\left[\mathrm{C}_{1} \mathrm{mIm}^{+}\right]$were investigated by high-energy total scattering (HETS) experiments. The nearest neighboring cation-anon orientation variations by the $N$-methyl groups substitution to proton were suggested based on the peaks at around 6 and $9 \AA$ in the differential radial distribution functions as the form of $r^{2}\left\{G^{\mathrm{X} \text {-ray }}(r)-1\right\}$ for these ionic liquids. It was supposed that the $\mathrm{NH} \cdots \mathrm{O}$ hydrogen bond causes the cation-anion orientation variations. To obtain further insight into the hydrogen bond in the PIL, MD simulations performed and agreed well with the experiments. According to spatial distribution functions (SDF) for the three ionic liquids, the $\mathrm{O}$ atom of $\mathrm{TFSA}^{-}$prefers the $\mathrm{NH}$ hydrogen of the imidazolium that has the most positive partial atomic charge in the cation, while the $\mathrm{F}$ atom locates right above and right below the imidazolium ring plane. In addition, the $\mathrm{NH} \cdots \mathrm{O}$ hydrogen bond has short bond lengths and linear bond angles, while the $\mathrm{C}_{2} \mathrm{H} \cdot \mathrm{O}$ interaction is long and bent. The $\mathrm{NH} \cdots \mathrm{O}$ hydrogen bond in the PIL was discussed based on structural aspect accompanied by a thermodynamic viewpoint.
\end{abstract}




\section{Keywords}

Hydrogen bond, Protic ionic liquids, X-ray scattering, MD simulations

\section{Introduction}

Protic ionic liquids (PIL) are one of the subclasses of ionic liquids [1, 2]. PIL $\left[\mathrm{HB}^{+}\right]\left[\mathrm{A}^{-}\right]$can be simply prepared by mixing a Brønsted acid HA and a base B $[3,4]$. Nowadays, lots of PIL were reported that consists of various cation and anion $[5,6]$ and have been well reviewed. [7-10]. PIL has attracted much attention as new proton conductors for a new class of fuel cells [11-14], so that the proton conduction mechanisms in PIL have also been investigated by means of the pulse gradient spin echo NMR technique [15-17]. More recently, novel PIL applications were proposed such as the $\mathrm{N}$ doped carbon materials utilized PIL as a starting material $[18,19]$.

Much effort has been made to quantify the cation-anion interactions in PIL as the Watanabe's Ionisity [20-23], and/or those estimated from the Walden plots [24-26]. Among them, the $\Delta \mathrm{p} K_{\mathrm{a}}$ proposed by Angell et al. [26, 27] can be a better measure for the cation-anion interactions in PIL and may be most used. $\Delta \mathrm{p} K_{\mathrm{a}}$ is defined as the difference between the acid dissociation constants $K_{\mathrm{a}}$ for $\mathrm{HA}$ and $\mathrm{HB}^{+}$in the aqueous solutions and well correlates with the Watanabe's Ionisity. Watanabe et al. found various physicochemical properties of PIL correlate with the $\Delta \mathrm{p} K_{\mathrm{a}}[28,29]$. Moreover, they pointed out possibility of the low-barrier hydrogen bond in PIL [30]. All these solvent parameters are rather useful for understanding the macroscopic thermodynamic/transport properties of PIL.

From the structural viewpoint, the cation-anion interactions in PIL were well studied until now [31-34], particularly focusing on the hydrogen bond. Ludwig et al. studied the cation-anion interactions in PIL by means of far-IR and DFT calculations. They demonstrated that the PIL form three-dimensional hydrogen network structure on the basis of similarity of far-IR spectra for alkylammonium nitrate protic ionic liquids to that of water, and found that a nice linear relationship between the peak positions in far-IR spectra and the binding energy between cation and anion in the PIL [33, 35-39]. They also reported such correlations can be found in imidazolium based ionic liquids [40, 41].

On the other hand, the knowledge from X-ray/neutron liquid structural studies can yield a clear picture to reveal interactions among the solvents; i.e., the cation-anion 
interactions in PIL, especially the hydrogen bond at a molecular level. Hayes and Atkin et al. have reported liquid structure of alkylammonium and their analogues based PIL elucidated by small/large angle neutron scattering techniques [42-46]. They found that bi- or trifurcated hydrogen bonding results, leading to weaker, bent hydrogen bonds, decreasing cation-anion attractions and leading to a more fluid-like material, whilst attractions between ions increase and physical properties become more solid-like when the nanostructures have a relatively high proportion of hydrogen bonds are linear. However, liquid structural investigation is limited to the ammonium based PIL at the present stage [47-53], though numerous publications have been made on the imidazolium based PIL.

We have reported the acid-base property of PIL. Although the $\Delta \mathrm{p} K_{\mathrm{a}}$ is better as the solvent parameter for not only the inter-ionic interactions in PIL but also various static/dynamic macroscopic properties of PIL, the auto-protolysis constant $K_{\mathrm{s}}$ could be more suitable for representing the acid-base property as they are determined on the basis of directly measured $\mathrm{pH}$ in PIL [54-56]. Recently, we extended our work to the $N$-methylimidazolium $\left[\mathrm{C}_{1} \mathrm{hIm}^{+}\right]$based PIL combined with various conjugated anions from super to weak acids [56]. According to the $\mathrm{p} K_{\mathrm{s}}$, proton transfer from the acetic/formic acid to the base is unfavorable, i.e., these equimolar mixtures yield simple electrically neutral non-aqueous solvent mixtures, not PIL. Nevertheless, significant molar ionic conductivity was found in the $N$-methylimidazole and acetic acid equimolar mixture. We thus proposed such liquids can be called as the pseudo-protic ionic liquids [57]. On the other hand, the cation and the corresponding anion predominantly exist in $\left[\mathrm{C}_{1} \mathrm{hIm}^{+}\right]\left[\mathrm{TFSA}^{-}\right]$(TFSA: bis-(trifluoromethanesulfonyl)amide) and $\left[\mathrm{C}_{1} \mathrm{hIm}^{+}\right]\left[\mathrm{TFS}^{-}\right]$ (TFS: trifluoromethanesulfonate), therefore these are essentially PIL. Raman spectroscopic speciation analysis and X-ray structural studies agree well with the $\mathrm{p} K_{\mathrm{s}}$ conclusion. [58]

In this paper, we investigated liquid structures of the TFSA $^{-}$based protic and aprotic ionic liquids composed of imidazolium $\left[\mathrm{h}_{2} \mathrm{Im}^{+}\right], N$-methylimidazolium $\left[\mathrm{C}_{1} \mathrm{hIm}^{+}\right]$and $N, N^{\prime}$-dimethylimidazolium $\left[\mathrm{C}_{1} \mathrm{mIm}^{+}\right]$by means of high-energy X-ray total scattering (HEXTS) experiments with the aid of MD simulations that well reproduced experimental X-ray structure factors. To the best of our knowledge, liquid structure of the imidazolium based PIL is reported for the first time as only the neutron diffraction of $\left[\mathrm{C}_{1} \mathrm{mIm}^{+}\right]\left[\mathrm{TFSA}^{-}\right]$have been published among ionic liquids examined here [59]. The closest cation-anion interactions, particularly the $\mathrm{NH} \cdots \mathrm{O}$ hydrogen bond was discussed by using spatial distribution functions (SDF) and pair correlation functions evaluated with the MD simulations. 


\section{Material and methods}

\section{Materials}

For aprotic ionic liquid, $\left[\mathrm{C}_{1} \mathrm{mIm}^{+}\right]\left[\mathrm{Cl}^{-}\right]$was purchased from Tokyo Chemical Industry co. ltd., and was used without further purification. $\left[\mathrm{C}_{1} \mathrm{mIm}^{+}\right]\left[\mathrm{TFSA}^{-}\right]$was prepared by treating $\left[\mathrm{C}_{1} \mathrm{mIm}^{+}\right]\left[\mathrm{Cl}^{-}\right]$with HTFSA in an aqueous solution, then $\mathrm{HCl}$ and solvent water were repeatedly evaporated under reduced pressure to confirm neutral $\mathrm{pH}$ and a negligible $\mathrm{AgNO}_{3}$ test. For preparation of protic ionic liquids, HTFSA and imidazole were sublimated under $\mathrm{N}_{2}$ atmosphere to remove water and purify, and $\mathrm{N}$-methylimidazole was stored with molecular sieve 4A to reduce water content under $100 \mathrm{ppm}$, then distilled under Ar atmosphere. Protic ionic liquids $\left[\mathrm{h}_{2} \mathrm{Im}^{+}\right]\left[\mathrm{TFSA}^{-}\right]$and $\left[\mathrm{C}_{1} \mathrm{hIm}^{+}\right]\left[\mathrm{TFSA}^{-}\right]$were prepared by mixing equivalent amount of HTFSA and imidazole/ $N$-methylimidazole. The sample preparation and treatment were performed in the glove box of Ar atmosphere with a water content kept less than $1 \mathrm{ppm}$. Finally, purity and water content of all of the sample ionic liquids were checked by elemental analysis and the Karl Fischer titration, respectively. Properties of all ionic liquids studied here are listed in Table 1.

\section{High-energy X-ray Total Scattering}

The HEXTS measurements were carried out using a two-axis diffractometer at the BL04B2 beam-line of SPring-8 at the Japan Synchrotron Radiation Research Institute (JASRI) [60, 61]. The ionic liquid samples were set in a hermetically sealed capillary Pyrex glass tube of $3.5 \mathrm{~mm}$ diameter and $0.1 \mathrm{~mm}$ thickness. Monochrome $61.6 \mathrm{keV}$ X-rays were obtained using a Si (220) monochromator. The observed X-ray intensity was corrected for absorption [62] and polarization. Incoherent scatterings [63-65] were subtracted to obtain coherent scatterings, $I_{\text {coh }}(Q)$. The X-ray structure factor $S^{\mathrm{X} \text {-ray }}(Q)$ and X-ray radial distribution function $G^{\mathrm{X}-\text { ray }}(r)$ per stoichiometric volume were respectively obtained according to

$$
\begin{aligned}
& S^{\mathrm{X} \text {-ray }}(Q)=\frac{I_{\text {coh }}(Q)-\sum n_{i} f_{i}(Q)^{2}}{\left(\sum n_{i} f_{i}(Q)\right)^{2}}+1 \\
& G^{\mathrm{X} \text {-ray }}(r)-1=\frac{1}{2 \pi^{2} r \rho_{0}} \int_{0}^{Q \max } Q\left\{S^{\mathrm{X}-\text { ray }}(Q)-1\right\} \sin (Q r) \exp \left(-B Q^{2}\right) d Q
\end{aligned}
$$


where $n_{i}$ and $f_{i}(Q)$ denote the number and the atomic scattering factor of atom $i$ [66], respectively, $\rho_{0}$ is the number density, and $B$ is the damping factor. All data treatment was carried out using the program KURVLR [67].

\section{Ab initio calculations}

For the partial atomic charges of the cations, all of the ab initio calculations were carried out at the MP2/cc-pVTZ(-f) level of theory, followed by partial charge evaluations at the MP2 density using the ChelpG methods [68]. Gaussian03 program suite was used. [69]. Thus Evaluated atomic partial charges are listed in Table 2.

\section{MD simulations}

MD simulations of an NTP ensemble, i.e., 256 ion pairs in a cubic cell at temperatures corresponding respective experiment and atmospheric pressure, controlled by Nose's thermostat [70, 71] and Parrinello-Rahman's barostat [72, 73] were carried out. Basically, all MD simulations carried out based on the CLaP (originally the OPLS-AA/Amber [74]) manner [74-79]. Lennard-Jones (LJ) and Coulomb terms were taken into account for the inter-molecular interactions. In MD simulations for $\left[\mathrm{C}_{1} \mathrm{mIm}^{+}\right]\left[\mathrm{TFSA}^{-}\right]$and $\left[\mathrm{C}_{1} \mathrm{hIm}^{+}\right]\left[\mathrm{TFSA}^{-}\right]$, the original CLaP force fields were employed. On the other hand, for $\left[\mathrm{h}_{2} \mathrm{Im}^{+}\right]\left[\mathrm{TFSA}^{-}\right]$, due to lack in the CLaP force fields, the partial atomic charges had been estimated as aforementioned, then determined with considering transferability among all ionic liquids studied here and with keeping consistency with the CLaP force fields. Finally employed partial atomic charges are listed in Table 2. The long-range interactions were treated by Ewald's method with the typical cutoff of $11 \AA$. The simulation time was 2 ns with a time step of 0.2 fs. It took $1.5 \mathrm{~ns}$ for the system equilibration, followed by the 0.5 ns production run. All simulations were carried out using Materials Explorer 5.0 MD program package with a graphical user interface (Fujitsu).

Experimental density values for the ionic liquids were 1.557 at $298 \mathrm{~K}$ for $\left[\mathrm{C}_{1} \mathrm{mIm}^{+}\right]\left[\mathrm{TFSA}^{-}\right], 1.614$ and $1.552 \mathrm{~g} \mathrm{~cm}^{-3}$ at 298 and $383 \mathrm{~K}$, respectively, for $\left[\mathrm{C}_{1} \mathrm{hIm}^{+}\right]\left[\mathrm{TFSA}^{-}\right]$and $1.657 \mathrm{~g} \mathrm{~cm}^{-3}$ at $388 \mathrm{~K}$ for $\left[\mathrm{h}_{2} \mathrm{Im}^{+}\right]\left[\mathrm{TFSA}^{-}\right]$. Corresponding simulated density values were $1.623,1.699,1.625$, and 1.719 for the respective ionic liquid. The relative deviations were 4.2, 5.3, 4.7 and $3.7 \%$, respectively.

The X-ray structure factor $S^{\mathrm{MD}}(Q)$ was calculated as: 


$$
\left\{\begin{array}{l}
S^{\mathrm{MD}}(Q)=\frac{\sum_{i} \sum_{j}\left\{n_{i}\left(n_{j}-1\right) f_{i}(Q) f_{j}(Q) / N(N-1)\right\}}{\left\{\sum_{k}\left(n_{k} f_{k}(Q) / N\right)\right\}^{2}} \int_{0}^{r} 4 \pi r^{2} \rho_{0}\left(g_{i j}^{\mathrm{MD}}(r)-1\right) \frac{\sin (Q r)}{Q r} d r+1 \quad(i=j) \\
S^{\mathrm{MD}}(Q)=\frac{\sum_{i} \sum_{j}\left(2 n_{i} n_{j} f_{i}(Q) f_{j}(Q) / N^{2}\right)}{\left\{\sum_{k}\left(n_{k} f_{k}(Q) / N\right)\right\}^{2}} \int_{0}^{r} 4 \pi r^{2} \rho_{0}\left(g_{i j}^{\mathrm{MD}}(r)-1\right) \frac{\sin (Q r)}{Q r} d r+1 \quad(i \neq j)
\end{array}\right.
$$

(4),

where $\rho_{0}$ denotes the ensemble average of the number density, and the total number of atoms in the simulation box $N$ is given by

$N=\sum_{k} n_{k}$

The X-ray radial distribution function $G^{\mathrm{MD}}(r)$ was obtained from $S^{\mathrm{MD}}(Q)$ by a Fourier transform procedure similar to that of $S^{\mathrm{X} \text {-ray }}(Q)$.

\section{Results and discussion}

X-ray structure factors $S^{\mathrm{x}-\text { ray }}(Q)$ for $\left[\mathrm{C}_{1} \mathrm{mIm}^{+}\right]\left[\mathrm{TFSA}^{-}\right]$and $\left[\mathrm{C}_{1} \mathrm{hIm}^{+}\right]\left[\mathrm{TFSA}^{-}\right]$at 298 $\mathrm{K}$ and those for $\left[\mathrm{C}_{1} \mathrm{hIm}^{+}\right]\left[\mathrm{TFSA}^{-}\right]$and $\left[\mathrm{h}_{2} \mathrm{Im}^{+}\right]\left[\mathrm{TFSA}^{-}\right]$at around $380 \mathrm{~K}$ are shown in Fig. 2a and 2b, respectively. According to our previous studies [80-83], the TFSA ${ }^{-}$ based aprotic ionic liquids have 2 characteristic peaks at a low $Q$ region of $Q<2.0 \AA^{-1}$. As shown in Fig. 2a and 2b, in all $S^{\mathrm{X}-\text { ray }}(Q)$ examined here 2 peaks of around 0.9 and 1.4 $\AA^{-1}$ characteristic to the TFSA ${ }^{-}$based ionic liquids observed regardless of whether aprotic or protic ionic liquids. The lowest $Q$ peaks appeared at $0.9 \AA^{-1}$ for $\left[\mathrm{C}_{1} \mathrm{mIm}^{+}\right]\left[\mathrm{TFSA}^{-}\right]$and $\left[\mathrm{C}_{1} \mathrm{hIm}^{+}\right]\left[\mathrm{TFSA}^{-}\right]$with higher peak intensity for $\left[\mathrm{C}_{1} \mathrm{mIm}^{+}\right]\left[\mathrm{TFSA}^{-}\right]$relative to $\left[\mathrm{C}_{1} \mathrm{hIm}^{+}\right]\left[\mathrm{TFSA}^{-}\right]$. Meanwhile, the second peaks were observed at around 1.4 and $1.3 \AA^{-1}$, for $\left[\mathrm{C}_{1} \mathrm{mIm}^{+}\right]\left[\mathrm{TFSA}^{-}\right]$and $\left[\mathrm{C}_{1} \mathrm{hIm}^{+}\right]\left[\mathrm{TFSA}^{-}\right]$, respectively, with lower peak intensity for $\left[\mathrm{C}_{1} \mathrm{mIm}^{+}\right]\left[\mathrm{TFSA}^{-}\right]$. Comparison among the $S^{\mathrm{X} \text {-ray }}(Q)$ for these ionic liquids indicates that the intermediate $r$ range atom-atom correlations such as those involved in the closest cation-anion are enhanced for $\left[\mathrm{C}_{1} \mathrm{hIm}^{+}\right]\left[\mathrm{TFSA}^{-}\right]$protic ionic liquid, while the reverse is the case for those in the second layer similar with long range ordering. Both peak position and intensity for $\left[\mathrm{C}_{1} \mathrm{hIm}^{+}\right]\left[\mathrm{TFSA}^{-}\right]$and $\left[\mathrm{h}_{2} \mathrm{Im}^{+}\right]\left[\mathrm{TFSA}^{-}\right]$are similar with each other at around $0.9 \AA^{-1}$. 
However, small but significant difference in intensity were found in the second peak at around $1.3 \AA^{-1}$; i.e., more intense peak was observed for $\left[\mathrm{h}_{2} \mathrm{Im}^{+}\right]\left[\mathrm{TFSA}^{-}\right]$with a shorter peak position. In addition, it is worth mentioning the small temperature dependence of the X-ray structure factor for $\left[\mathrm{C}_{1} \mathrm{hIm}{ }^{+}\right]\left[\mathrm{TFSA}^{-}\right]$; i.e., peak positions were shifted toward lower $Q$ with a small change in peak intensity when elevating temperature. Small temperature dependence that has been also observed those for 1-butyl-3-methylimidazolium halide aprotic ionic liquids suggests that inter-ionic potentials for the ionic liquids are deep and sweep probably due to the strong Coulombic interactions. [84]

The corresponding differential radial distribution functions as the form of $r^{2}\left\{G^{\mathrm{X} \text {-ray }}(r)-1\right\}$ are displayed in Fig 2c and 2d. For $\left[\mathrm{C}_{1} \mathrm{mIm}^{+}\right]\left[\mathrm{TFSA}^{-}\right]$and $\left[\mathrm{C}_{1} \mathrm{hIm}^{+}\right]\left[\mathrm{TFSA}^{-}\right]$at $298 \mathrm{~K}$, the amplitude of the peak at around $6 \AA^{-1}$ for $\left[\mathrm{C}_{1} \mathrm{mIm}^{+}\right]\left[\mathrm{TFSA}^{-}\right]$is slightly smaller than that of $\left[\mathrm{C}_{1} \mathrm{hIm}^{+}\right]\left[\mathrm{TFSA}^{-}\right]$with almost the same peak position. The second peak at around $9 \AA$ for $\left[\mathrm{C}_{1} \mathrm{mIm}^{+}\right]\left[\mathrm{TFSA}^{-}\right]$shifts toward longer side with reducing in the amplitude by one $N$-methyl group substitution to proton. In addition, the third and forth peaks at around 15 and $22 \AA$ can be found for both ionic liquids. Spatial density fluctuations are almost identical in the further $r$ range of $r>12$ $\AA$. This means liquid structures of both $\left[\mathrm{C}_{1} \mathrm{mIm}^{+}\right]\left[\mathrm{TFSA}^{-}\right]$and $\left[\mathrm{C}_{1} \mathrm{hIm}^{+}\right]\left[\mathrm{TFSA}^{-}\right]$are practically the same in longer range of $r>12 \AA$. Similar difference can be found in the $r^{2}\left\{G^{\mathrm{X} \text {-ray }}(r)-1\right\}$ of $\left[\mathrm{C}_{1} \mathrm{hIm}^{+}\right]\left[\mathrm{TFSA}^{-}\right]$and $\left[\mathrm{h}_{2} \mathrm{Im}^{+}\right]\left[\mathrm{TFSA}^{-}\right]$at around $380 \mathrm{~K}$. Thus, from the differential radial distribution functions, it is deduced that the experimentally observed structural changes in the second sphere ions of the same sign are caused by orientation changes in the nearest neighboring cation-anion with the stepwise substitution of the $N$-methyl group to proton without significant change in longer range ordering of $r>12 \AA$. The substituted hydrogen from the $N$-methyl group can reduce the anion excluded volume significantly. Moreover, according to Tsuzuki et al., the $\mathrm{CH} \cdots \mathrm{X}$ interaction of the imidazolium ring hydrogen has little orientation dependence though it approaches to linear as increasing the counter anion hydrogen bonding ability.[86] Meanwhile, the $\mathrm{NH} \cdots \mathrm{O}$ hydrogen bond should be linear. Hence, the introduction of the $\mathrm{NH} \cdots \mathrm{O}$ hydrogen bond instead of the $\mathrm{CH}_{3} \cdots \mathrm{O}$ interaction could change the orientation among the ions of the same sign on the second layer but never perturb longer range liquid structure of $r>12 \AA$.

To yield further insight, we attempted to perform MD simulations. However, the force fields for $\mathrm{h}_{2} \mathrm{Im}^{+}$were not available until now, so that the force fields parameters were developed according to the CLaP one. In the framework of the CLaP force fields, partial atomic charges are evaluated on the basis of ab initio calculations with the ESP 
fitting [73]. We obeyed the CLaP manner and thus evaluated partial atomic charges are listed in Table 2 together with the atomic charges for MD simulations for comparison. Here, ab initio partial atomic charges are insightful. Two weakly positive charges exist in $\mathrm{C}_{1} \mathrm{mIm}^{+}$; 0.135 for the $N$-methyl hydrogen and 0.202 for the ring hydrogen. One $\mathrm{N}$-methyl group substitution to proton slightly increase charge on the remained $N$-methyl hydrogen of 0.15 and fairly decrease the ring hydrogen charge of 0.195 , and put a large positive charge on the $\mathrm{NH}$ hydrogen of 0.365 . Further substitution causes similar variations; 0.195 on the ring hydrogen and 0.353 on the NH hydrogen. Namely, spatially scattered weak positive charges on the $N$-methyl hydrogen are forced to concentrate on the rather large positive charge on the NH hydrogen, which could lead to attract the negatively charged anion $\mathrm{O}$ atoms around the $\mathrm{NH}$ hydrogen. Later, we will discuss in detail by using spatial distribution functions SDF derived from the MD simulations.

MD simulations well reproduced experimental density and total X-ray structure factors for all of the ionic liquids studied here. As aforementioned, it is supposed that the closest cation-anion orientations and the second layer configurations among the ions of the same sign are varied by the introduction of the imidazolium $\mathrm{NH}$. Therefore, the inter-molecular radial distribution function $G_{\text {inter }}(r)$ is valuable. Comparison between experimental and simulated $G_{\text {inter }}(r)$ is shown in Fig. 3. Although experimental $G_{\text {inter }}(r)$ are scattered, simulated $G_{\text {inter }}(r)$ well reproduced experimental ones.

The center of masses pair correlation functions of the first layer cation-anion and the second layer cation-cation and anion-anion are represented in Fig 4 for all ionic liquids studied here. We analyzed the cation-anion pair correlation functions by non-linear least fitting with the Gaussian distributions to evaluate the peak position and the coordination number. The results listed in Table 3. Although the difference between $\left[\mathrm{C}_{1} \mathrm{mIm}^{+}\right]\left[\mathrm{TFSA}^{-}\right]$and $\left[\mathrm{C}_{1} \mathrm{hIm}^{+}\right]\left[\mathrm{TFSA}^{-}\right]$in the experimental inter-ionic radial distribution function were not clear, the structural changes in the first layer cation-anion among these ionic liquids are clearly shown in the figures; two peaks appear around $5 \AA$ for $\left[\mathrm{C}_{1} \mathrm{mIm}^{+}\right]\left[\mathrm{TFSA}^{-}\right]$, more intense peak with shoulder at the further side is found for $\left[\mathrm{C}_{1} \mathrm{hIm}^{+}\right]\left[\mathrm{TFSA}^{-}\right]$. In addition, the second layer cation-cation center of masses pair correlation functions significantly differ from each other, while that of the anion-anion seems to be similar. Hence, the experimentally found structural changes at $r<12 \AA$ can be ascribed to the changes in the nearest neighboring cation-anion orientation and those in the second layer ions configuration. Though small relative to the above difference, but significant variations can be found for the center of masses pair correlation functions for $\left[\mathrm{C}_{1} \mathrm{hIm}^{+}\right]\left[\mathrm{TFSA}^{-}\right]$and $\left[\mathrm{h}_{2} \mathrm{Im}^{+}\right]\left[\mathrm{TFSA}^{-}\right]$. The most characteristic difference 
is sharpened peaks in the cation-anon and the cation-cation pair correlation functions for $\left[\mathrm{h}_{2} \mathrm{Im}^{+}\right]\left[\mathrm{TFSA}^{-}\right]$comparing with those for $\left[\mathrm{C}_{1} \mathrm{hIm}^{+}\right]\left[\mathrm{TFSA}^{-}\right]$. The sharpened peaks suggests that the reduced excluded volume and the introduction of the strong $\mathrm{NH}^{\circ} \mathrm{O}$ hydrogen bond of shorter and more linear than the $\mathrm{CH} \cdots \mathrm{O}$ interactions could tighten the first and the second layers structure of $\left[\mathrm{h}_{2} \mathrm{Im}^{+}\right]\left[\mathrm{TFSA}^{-}\right]$relative to $\left[\mathrm{C}_{1} \mathrm{hIm}^{+}\right]\left[\mathrm{TFSA}^{-}\right]$. Interestingly, the coordination numbers for these ionic liquids are rather different among them. It may arise from difference in spatial distributions of the anion around the cation, vice versa.

SDF is convenient for discussion on the closest cation-anion orientations and the second sphere ions of the same sign configurations. Center of masses of the closest anion and cation SDF around cation are depicted in Fig. 5. The center of mass of the nearest neighboring anion SDF for $\left[\mathrm{C}_{1} \mathrm{mIm}^{+}\right]\left[\mathrm{TFSA}^{-}\right]$is similar with those for the 1-alkyl-3-methylimidazorium aprotic ionic liquids except symmetry [79-82]; i.e., the anion predominantly locates at above and below the imidazolium ring plane around the $\mathrm{C}_{2} \mathrm{H}$, and vicinity around the $\mathrm{C}_{4} \mathrm{H} / \mathrm{C}_{5} \mathrm{H}$. The second layer cation around the cation distributes every other position of the closet anion; the cation locates toward the orientations of the $\mathrm{N}$-methyl groups and the center between the $\mathrm{C}_{4} \mathrm{H}$ and the $\mathrm{C}_{5} \mathrm{H}$ beyond the first layer anion. With regard to $\left[\mathrm{C}_{1} \mathrm{hIm}^{+}\right]\left[\mathrm{TFSA}^{-}\right]$, predominant population of the closest anion moves to around the $\mathrm{NH}$ hydrogen with remaining significant distribution around the $\mathrm{C}_{2} \mathrm{H}$. Interestingly, the second layer cation mostly locates beyond the $\mathrm{NH} \cdots \mathrm{O}$ hydrogen bonded anion. The nearest neighboring anion distribution in $\left[\mathrm{h}_{2} \mathrm{Im}^{+}\right]\left[\mathrm{TFSA}^{-}\right]$is practically identical with those around the $\mathrm{NH}$ hydrogen side in $\left[\mathrm{C}_{1} \mathrm{mIm}^{+}\right]\left[\mathrm{TFSA}^{-}\right]$. Similarly, the second layer cation population is resemble those around the $\mathrm{NH}$ hydrogen side in $\left[\mathrm{C}_{1} \mathrm{hIm}^{+}\right]\left[\mathrm{TFSA}^{-}\right]$. It is worth mentioning hydrogen bonded linear network liquid structure seems to be formed in $\left[\mathrm{h}_{2} \mathrm{Im}^{+}\right]\left[\mathrm{TFSA}^{-}\right]$due to tits symmetric imidazolium $\mathrm{NH}$.

SDF for the $\mathrm{O}$ and the $\mathrm{F}$ atoms in the TFSA ${ }^{-}$around the cation are shown in Fig. 6 accompanied by electrostatic potentials of the cations for comparison. With regard to $\left[\mathrm{C}_{1} \mathrm{mIm}^{+}\right]\left[\mathrm{TFSA}^{-}\right]$, the $\mathrm{O}$ atom $\mathrm{SDF}$ is resemble with those for 1-alkyl-3-methylimidazorium based ionic liquids as well as the center of masses SDF, [79-82]; i.e., the $\mathrm{O}$ atoms are mainly locates around the $\mathrm{C}_{2} \mathrm{H}$, the $\mathrm{C}_{4} \mathrm{H}$ and the $\mathrm{C}_{5} \mathrm{H}$ symmetrically, above and below the imidazolium ring. Please note that positive charges are similarly distributed around the $\mathrm{C}_{2} \mathrm{H}$, the $\mathrm{C}_{4} \mathrm{H}$ and the $\mathrm{C}_{5} \mathrm{H}$ in the $\mathrm{C}_{1} \mathrm{mIm}^{+}$cation. Oppositely, the $\mathrm{F}$ atom in the TFSA ${ }^{-}$predominantly exists right above and right below the imidazolium ring plane with small population around the $N$-methyl group. On the other hand, with $\left[\mathrm{C}_{1} \mathrm{hIm}^{+}\right]\left[\mathrm{TFSA}^{-}\right]$, the $\mathrm{O}$ atoms are asymmetrically distributed around the $\mathrm{NH}$ and the $\mathrm{C}_{2} \mathrm{H}$ with slight density around the $\mathrm{C}_{5} \mathrm{H}$ at $298 \mathrm{~K}$ as easily expected. When elevating temperature to $383 \mathrm{~K}$, the population around the $\mathrm{NH}$ is almost identical that at $298 \mathrm{~K}$, while those around the $\mathrm{C}_{2} \mathrm{H}$ and the $\mathrm{C}_{5} \mathrm{H}$ decrease and disappear, respectively. This clearly suggests that the $\mathrm{O}$ atoms favor the $\mathrm{NH}$ rather than the other positively charged the ring and/or the $N$-methyl hydrogen. Though the $\mathrm{F}$ atom population scatters at $298 \mathrm{~K}$, it clearly locates right above and right below the 
imidazolium ring as well as $\mathrm{C}_{1} \mathrm{mIm}^{+}$. For $\mathrm{h}_{2} \mathrm{Im}^{+}$, the large $\mathrm{O}$ atom density locates around the $\mathrm{NH}$ symmetrically, while the $\mathrm{F}$ atom distributes by similar way with the others. It should be noted that the most positive electrostatic potential in the $\mathrm{h}_{2} \mathrm{Im}^{+}$ cation is around the $\mathrm{NH}$ due to the large positive charge of 0.35 on the HN hydrogen. Hence, the $\mathrm{h}_{2} \mathrm{Im}^{+}$strongly interacts with just the $\mathrm{O}$ atom around the $\mathrm{NH}$. As previously pointed out, an atomistic HSAB rule could be applied to ionic liquids i.e., the harder $\mathrm{O}$ atom prefers the harder interaction site with the electrostatic interaction, whilst the softer $\mathrm{F}$ atom favors the softer site probably with the polarization interaction [83]. The atomistic HSAB rule could be more clearly found in protic ionic liquids.

As pointed out by Ueno and Watanabe et al. [85], directionality of interaction is important for ionic liquids, particularly for protic ones [34, 86] because a hydrogen bond has a direction in itself. For obtaining more detailed information about the hydrogen bond in the imidazolium based PIL, the bond length and the bond angle were estimated. Partial atom-atom pair correlation functions $g(r)$ for $\left[\mathrm{C}_{1} \mathrm{mIm}^{+}\right]\left[\mathrm{TFSA}^{-}\right]$and $\left[\mathrm{C}_{1} \mathrm{hIm}^{+}\right]\left[\mathrm{TFSA}^{-}\right]$at $298 \mathrm{~K}$ and those for $\left[\mathrm{C}_{1} \mathrm{hIm}^{+}\right]\left[\mathrm{TFSA}^{-}\right]$and $\left[\mathrm{h}_{2} \mathrm{Im}^{+}\right]\left[\mathrm{TFSA}^{-}\right]$at around $380 \mathrm{~K}$ are shown in Fig. $7(\mathrm{a})$ and (b), respectively. As expected, the $\mathrm{C}_{2} \mathrm{H} \cdots \mathrm{O}$ lengths are practically the same both in aprotic and protic ionic liquids and longer than those of the $\mathrm{NH} \cdots \mathrm{O}$. Similarly, the $\mathrm{NH} \cdots \mathrm{O}$ lengths are almost identical both in symmetric and asymmetric imidazolium based protic ionic liquids. It should be noted that the $\mathrm{NH} \cdots \mathrm{O}$ hydrogen bond lengths of about $1.7-1.8 \AA$ evaluated here is rather short. By using the Bondi's van der Waals radii [87, 88] and employing $80 \%$ shorter than the sum of them as the short contact interaction, we can easily obtain $2.09-2.18 \AA$ for $\mathrm{NH} \cdots \mathrm{O}$ short contact depending on the VDW radii for a hydrogen atom, which is significantly distinguishable from 1.7 - $1.8 \AA$. The bond angles are listed in Table 4 that were estimated with the distributions of the inter-molecular $\mathrm{NH} \cdots \mathrm{O}$ and the intra-molecular $\mathrm{N}-\mathrm{H}$ lengths in simulations. As clearly shown in Table 4, the $\mathrm{NH}^{\cdots} \mathrm{O}$ angles are relatively liner of ranging $160^{\circ}-166^{\circ}$ for both protic ionic liquids. On the other hand, the $\mathrm{C}_{2} \mathrm{H} \cdots \mathrm{O}$ angles distribute in the range of $123^{\circ}-142^{\circ}$ regardless of whether aprotic or protic, which are rather distorted

In our previous study on the liquid structures of primary alkylammonium nitrate ionic liquids, we found unusual distorted $\mathrm{NH}^{\cdots} \mathrm{O}$ hydrogen bond in the protic ionic liquids [89, 90]. As mentioned in the introduction section, according to Hayes and Atkin et al. [46], the hydrogen bond nature of primary ammonium based ionic liquids can be classified in terms of the number of hydrogen bond acceptor atoms per ammonium hydrogen $R_{\mathrm{X}: \mathrm{HN}}$; i.e., when $R_{\mathrm{X}: \mathrm{HN}}$ is greater than 1 (bi- and tri-dentate hydrogen bond, though they called "bi- or trifurcated"), the hydrogen bond is longer than $2.0 \AA$ and such protic ionic liquids are liquid-like, meanwhile reverse the case for smaller $R_{\mathrm{X}: \mathrm{HN}}$ (mono-dentate hydrogen bond). As aforementioned, the imidazolium based protic ionic 
liquids have shorter $\mathrm{NH} \cdot$ O hydrogen bonds of $1.7-1.8 \AA$ with a nearly linear angle of $160^{\circ}-166^{\circ}$. In addition, the coordination numbers integrated $g_{\mathrm{NH} \cdot \cdot \mathrm{O}}(r)$ up to $2.50 \AA$ are about 1.1 - 1.2, suggesting the hydrogen bond is mono-dentate. Hence, the classification by Hayes and Atkin et al. can be applied to the imidazolium based PIL. However, warning is still needed for simple interpretation that the short and linear $\mathrm{NH} \cdots \mathrm{O}$ hydrogen bond would be strong. It should be noted that $\mathrm{TFSA}^{-}$is the conjugated anion of super-acid HTFSA. Therefore, although the ability as the hydrogen bond accepter and/or the electron pair donor of TFSA ${ }^{-}$should be quite weak, the imidazolium based PIL has a short hydrogen bond, which is probably due to spatial availability around the hydrogen bond donor/acceptor, that is, entropic contribution rather than enthalpic one. It is thus necessary to investigate the hydrogen bonds in the imidazolium based protic ionic liquids more systematically and in detail. Neutron diffraction experiments with the aid of MD simulations are now going on.

\section{Conclusions}

Liquid structures of $\left[\mathrm{C}_{1} \mathrm{mIm}^{+}\right]\left[\mathrm{TFSA}^{-}\right],\left[\mathrm{C}_{1} \mathrm{hIm}^{+}\right]\left[\mathrm{TFSA}^{-}\right]$and $\left[\mathrm{h}_{2} \mathrm{Im}^{+}\right]\left[\mathrm{TFSA}^{-}\right]$ionic liquids were revealed by the HEXTS experiments with the aid of MD simulations. $G^{\mathrm{X} \text {-ray }}(r)$ suggests the closest cation-anion orientation varies, leading to the second layer composed of the ions of the same sign configuration changes, without significant longer range ordering of $r>12 \AA$ by the $N$-methyl substitution to proton. It is deduced that the $\mathrm{NH}$ * O hydrogen bond causes the closest cation-anion orientation perturbation. MD simulations that agree with the experiments clearly exhibit the anion $\mathrm{O}$ atom of rather negative charge prefers the positively charged NH hydrogen or the imidazolium ring, hydrogen, whilst the anon $\mathrm{F}$ atom dominantly distributes right above and right below the imidazolium ring plane. Spatial distributions of the $\mathrm{O}$ and $\mathrm{F}$ atoms around the protic imidazolium in the PIL indicate an atomistic HASB rule could hold in the PIL rather than the corresponding aprotic one. The $\mathrm{NH} \cdots \mathrm{O}$ hydrogen bond is short and linear, while the $\mathrm{C}_{2} \mathrm{H} \cdots \mathrm{O}$ interaction is long and bent, which agrees with well established concept that the $\mathrm{NH} \cdots \mathrm{O}$ hydrogen bond is strong, whilst the $\mathrm{C}_{2} \mathrm{H} \cdots \mathrm{O}$ interaction is weak. Taking into consideration that TFSA ${ }^{-}$is quite weak in terms of the hydrogen bond accepter and/or the electron pair donor, the short and linear $\mathrm{NH} \cdots \mathrm{O}$ hydrogen bond between the protic imidazolium and the TFSA ${ }^{-}$implies that spatial availability, that is, the configuration entropy could contribute to the formation of the hydrogen bond in the imidazolium based PIL. 


\section{Acknowledgements}

This study was supported in part by the Grants-in-Aid for Scientific Research Nos. 23350033, 24655142 and 26.4098 from the Japan Society for the Promotion of Science (JSPS), and by the Advanced Low Carbon Technology Research and Development Program (ALCA) of the Japan Science and Technology Agency (JST). The synchrotron radiation HEXTS experiments were carried out with the approval of the Japan Synchrotron Radiation Research Institute (JASRI) (Proposal Nos. 2012A1571, 2012A1669, 2012A1682 and 2012B1709).

\section{References}

[1] C. A. Angell, Y. Ansari, Z. Zhao, Faraday Discuss., 154 (2012) 9-27.

[2] M. Armand1, F. Endres, D. R. MacFarlane, H. Ohno, B. Scrosati, Nature Mat, 8 (2009) 621.

[3] M. Yoshizawa, W. Ogihara, H. Ohno, Electrochem. Solid-State Lett., 4 (2001) E25-E27.

[4] H. Ohno, M. Yoshizawa, Solid State Ionics, 154-155 (2002) 303-309.

[5] T. L. Greaves, A. Weerawardena, I. Krodkiewska, C. J. Drummond, J. Phys. Chem. B, 112 (2008) 896-905.

[6] T. L. Greaves, K. Ha, B. W. Muir, S. C. Howard, A. Weerawardena, N. Kirby, C. J. Drummond, Phys. Chem. Chem. Phys., 17 (2015) 2357-2365.

[7] D. R. MacFarlane, J. M. Pringle, K. M. Johansson, S. A. Forsyth, M. Forsyth, Chem. Commun., 18 (2006) 1905-1917.

[8] T. L. Greaves, C. J. Drummond, Chem. Soc. Rev., 37 (2008) 1709-1726.

[9] T. L. Greaves, C. J. Drummond, Chem. Rev., 108 (2008) 206-237.

[10] T. L. Greaves, C. J. Drummond, Chem. Soc. Rev., 42 (2013) 1096-1120.

[11] W. Xu, C. A. Angell, Science, 302 (2003) 422-425.

[12] Md. A. B. H. Susan, A. Noda, S. Mistushima, M. Watanabe, Chem. Commun., 8 (2003) 938-939.

[13] H. Nakamoto, M. Watanabe, Chem. Commun., 24 (2007) 2539-2541.

[14] SY. Lee, A. Ogawa, M. Kanno, H. Nakamoto, T. Yasuda, M. Watanabe, J. Am. Chem. Soc., 132 (2010) 9764-9773.

[15] A. Noda, Md. A. B. H. Susan, K. Kudo, S. Mitsushima, K. Hayamizu, M. Watanabe, J. Phys. Chem. B, 107 (2003) 4024-4033.

[16] K. M. Johansson, E. I. Izgorodina, M. Forsyth, D. R. MacFarlane, K. R. Seddon, Phys. Chem. Chem. Phys., 10 (2008) 2972-2978. 
[17] M. L. Hoarfrost, M. Tyagi, R. A. Segalman, J. A. Reimer, J. Phys. Chem. B, 116 (2012) 8201-8209.

[18] S. Zhang, K. Dokko, M. Watanabe, Chem. Mater., 26 (2014) 2915-2926.

[19] S. Zhang, M. S. Miran, A. Ikoma, K. Dokko, M. Watanabe, J. Am. Chem. Soc., 136 (2014) 1690-1693.

[20] H. Tokuda, K. Hayamizu, K. Ishii, Md. A. B. H. Susan, M. Watanabe, J. Phys. Chem. B, 108 (2004) 16593-16600.

[21] H. Tokuda, K. Hayamizu, K. Ishii, Md. A. B. H. Susan, M. Watanabe, J. Phys. Chem. B, 109 (2005) 6103-6110.

[22] H. Tokuda, S. Tsuzuki, Md. A. B. H. Susan, K. Hayamizu, M. Watanabe, J. Phys. Chem. B, 110 (2006) 19593-19600.

[23] H. Tokuda, K. Ishii, Md. A. B. H. Susan, S. Tsuzuki, K. Hayamizu, M. Watanabe, J. Phys. Chem. B, 110 (2006) 2833-2839.

[24] D. R. MacFarlane, M. Forsyth, E. I. Izgorodina, A. P. Abbott, G. Annat, K. Fraser, Phys. Chem. Chem. Phys., 11 (2009) 4962-4967.

[25] C. A. Angell, N. Byrne, J.-P. Belieres, Acc. Chem. Res., 40 (2007) 1228.

[26] M. Yoshizawa, W. Xu, C. A. Angell, J. Am. Chem. Soc., 125 (2003) 15411-15419.

[27] J. P. Belieres, C. A. Angell, J. Phys. Chem. B, 111 (2007) 4926-4937.

[28] M. S. Miran, H. Kinoshita, T. Yasuda, Md. A. B. H. Susan, M. Watanabe, Phys. Chem. Chem. Phys., 14 (2012) 5178-5186.

[29] M. S. Miran, T. Yasuda, Md. A. B. H. Susan, K. Dokko, M. Watanabe, RCS Adv., 3 (2013) 4141-4144.

[30] M. S. Miran, H. Kinoshita, T. Yasuda, Md. A. B. H. Susan, M. Watanabe, Chem. Commun., 47 (2011) 12676-12678.

[31] K. Fumino, A. Wulf, R. Ludwig, Phys. Chem. Chem. Phys., 11 (2009) 8790-8794.

[32] A. Wulf, K. Fumino, R. Ludwig, Angew. Chem. Int. Ed., 49 (2010) 449-453.

[33] K. Fumino, E. Reichert, K. Wittler, R. Hempelmann, R. Ludwig, Angew. Chem. Int. Ed., 51 (2012) 6236-6240.

[34] S. Tsuzuki, W. Shinoda, Md. S. Miran, H. Kinoshita, T. Yasuda, M. Watanabe, J. Chem. phys., 139 (2013) 174504/1-174504/9.

[35] K. Fumino, A. Wulf, R. Ludwig, Angew. Chem. Int. Ed., 48 (2009) 3184-3186.

[36] K. Fumino, V. Fossog, K. Wittler, R. Hempelmann, R. Ludwig, Angew. Chem. Lnt. Ed., 52 (2013) 2368-2372.

[37] K. Fumino, V. Fossog, P. Stange, K. Wittler, W. Polet, R. Hempelmann, R. Ludwig, ChemPhysChem, 15 (2014) 2604-2609.

[38] K. Fumino, V. Fossog, P. Stange, D. Paschek, R. Hempelmann, R. Ludwig, Angew. 
Chem. Int. Ed., 54 (2015) 2792-2795.

[39] R. Ludwig, Phys. Chem. Chem. Phys., 17 (2015) 13790-13793.

[40] T. Peppel, C. Roth, K. Fumino, D. Paschek, M. Koeckerling, R. Ludwig, Angew. Chem. Int. Ed., 50 (2011) 6661-6665.

[41] K. Fumino, S. Reimann, R. Ludwig, Phys. Chem. Chem. Phys., 16 (2014) 21903-21929.

[42] R. Atkin, G. G. Warr, J. Phys. Chem. B, 112 (2008) 4164-4166.

[43] R. Hayes, S. Imberti, G. G. Warr, R. Atkin, Phys. Chem. Chem. Phys., 13 (2011) 3237-3247.

[44] R. Hayes, S. Imberti, G. G. Warr, R. Atkin, Phys. Chem. Chem. Phys., 13 (2011) 13544-13551.

[45] R. Hayes, S. Imberti, G. G. Warr, R. Atkin, J. Phys. Chem. C, 118 (2014) 13998-14008.

[46] R. Hayes, S. Imberti, G. Gregory, R. Atkin, Angew. Chem. Int. Ed., 52 (2013) 4623-4627.

[47] L. Gontrani, E. Bodo, A. Triolo, F. Leonelli, P. Dangelo, V. Migliorati, R. Caminiti, J. Phys. Chem. B, 116 (2012) 13024-13032.

[48] O. Russina, A. Sferrazza, R. Caminiti, A. Triolo, J. Phys. Chem. Lett., 5 (2014) 1738-1742.

[49] R. Hayes, S. A. Bernard, S. Imberti, G. G. Warr, R. Atkin, J. Phys. Chem. C, 118 (2014) 21251-21225.

[50] O. Russina, A. Mariani, R. Caminiti, A. Triolo, J. Sol. Chem., 44 (2015) 669-685.

[52] O. Russina, R. Caminiti, T. Mendez-Moreles, J. Carrete, O. Cabeza, L. G. Gallego, L. M. Varela, A. Triolo, J. Mol. Liq., 205 (2015) 16-21.

[53] O. Russina, M. Macchiagodena, B. Kirchner, A. Mariani, B. Aoun, M. Russina, R. Caminiti, A. Triolo, J. Non-Crystalline. Solids, 407 (2015) 333-338.

[54] R. Kanzaki, K. Uchida, S. Hara, Y. Umebayashi, S. Ishiguro, Chem. Lett., 36 (2007) 684-685.

[55] R. Kanzaki, X. Song, Y. Umebayashi, S. Ishiguro, Chem. Lett., 39 (2010) 578-579.

[56] R. Kanzaki, H. Doi, X. Song, S. Hara, S. Ishiguro, Y. Umebayashi, J. Phys. Chem. $B, 116$ (2012) 14146-14152.

[57] H. Doi, X. Song, B. Minofar, Ryo Kanzaki,T. Takamuku, Y. Umebayashi, Chem. Eur. J., 19 (2013) 11522-11526.

[58] H. Doi, H. Watanabe, S. Saito, K. Fujii, R. Kanzaki, Y. Kameda, Y. Umebayashi, J. Phys. Chem. B, (2015) to be submitted.

[59] M. Deetlefs, C. Hardacre, M. nieuwenhuzen, A. A. H. Padua, O. Sheppard, A. K. 
Soper, J. Phys. Chem. B, 110 (2006) 12055-12061.

[60] M. Isshiki, Y. Ohishi, S. Goto, K. Takeshita, K. Takeshita, T. Ishikawa, Nucl. Instrum. Meth. A, 663 (2001) 467-468.

[61] S. Kohara, K. Suzuya, Y. Kashihara, N. Matsumoto, N. Umesaki, I. Sakai, Nucl. Instrum. Meth. A, 1030 (2001) 467-468.

[62] S. Sasaki, KEK Report 90-16, National Laboratory for High Energy Physics, Japan (1991).

[63] J. H. Hubbell, W. J. Veigele, E. A. Briggs, R. T. Brown, D. T. Cromer, R. J. Howerton, J. Phys. Chem. Ref. Data, 4 (1975) 471.

[64] D. T. Cromer, J. Chem. Phys., 50 (1969) 4857.

[65] D. T. Cromer, J. B. Mann, J. Chem. Phys., 47 (1967) 1892.

[66] E. N. Maslen, A. G. Fox, M. A. O’Keefe, International Tables For Crystallography Vol. C, 572-574, Kluwer: Dorfrecht, 1999.

[67] G. Johanson, M. Sandstörm, Chem. Scr., 4 (1973) 195

[68] L. E. Chirlian, M. M. Francl, J. Comp. Chem., 8 (1987) 894-905.

[68] Gaussian 03, Revision D.01, M. J. Frisch, G. W. Trucks, H. B. Schlegel, G. E. Scuseria, M. A. Robb, J. R. Cheeseman, Jr., J. A. Montgomery, T. Vreven, K. N. Kudin, J. C. Burant, J. M. Millam, S. S. Iyengar, J. Tomasi, V. Barone, B. Mennucci, M. Cossi, G. Scalmani, N. Rega, G. A. Petersson, H. Nakatsuji, M. Hada, M. Ehara, K. Toyota, R. Fukuda, J. Hasegawa, M. Ishida, T. Nakajima, Y. Honda, O. Kitao, H. Nakai, M. Klene, X. Li, J. E. Knox, H. P. Hratchian, J. B. Cross, V. Bakken, C. Adamo, J. Jaramillo, R. Gomperts, R. E. Stratmann, O. Yazyev, A. J. Austin, R. Cammi, C. Pomelli, J. W. Ochterski,P. Y. Ayala, K. Morokuma, G. A. Voth, P. Salvador, J. J. Dannenberg, V. G. Zakrzewski, S. Dapprich, A. D. Daniels, M. C. Strain, O. Farkas, D. K. Malick, A. D. Rabuck, K. Raghavachari, J. B. Foresman, J. V. Ortiz, Q. Cui, A. G. Baboul, S. Clifford, J. Cioslowski, B. B. Stefanov, G. Liu, A. Liashenko, P. Piskorz, I. Komaromi, R. L. Martin, D. J. Fox, T. Keith, M. A. Al-Laham, C. Y. Peng, A. Nanayakkara, M. Challacombe, P. M. W. Gill, B. Johnson, W. Chen, M. W. Wong, C. Gonzalez, J. A . Pople, Gaussian, Inc., Wallingford CT, 2004.

[70] S. Nose, Mol. Phys., 52 (1984) 255.

[71] S. Nose, J. Chem. Phys., 81 (1984) 511.

[72] M. Parrinello, A Rahman, J. Phys. Rev. Lett., 45 (1980) 1196.

[73] M. Parrinello, A Rahman, J. Appl. Phys. 52 (1981) 7182.

[74] W. L. Jorgensen, D. S. Maxwell, J. Tirado-Rives, J. Am. Chem. Soc. 118 (1996) 11225.

[75] J. N. C. Lopes, J. Deschamps, A. A. H. Pádua, J. Phys. Chem. B, 108 (2004) 
2038-2047.

[76] J. N. C. Lopes, A. A. H. Pádua, J. Phys. Chem. B, 108 (2004) 16893-16898.

[77] J. N. C. Lopes, A. A. H. Pádua, J. Phys. Chem. B, 110 (2006) 19586-19592.

[78] J. N. C. Lopes, A. A. H. Pádua, K. Shimizu, J. Phys. Chem. B, 112 (2008) 5039-5046.

[79] K. Shimizu, D. Almantariatis, M. F. C. Gomes, A. A. H. Pảdua, J. N. C. Lopes, J. Phys. Chem. B, 114 (2010) 3592-3600.

[80] K. Fujii, Y. Soejima, Y. Kyoshoin, S. Fukuda, R. Kanzaki, Y. Umebayashi, T. Yamaguchi, S. Ishiguro, T. Takamuku, J. Phys. Chem. B, 112 (2008) 4329-4336.

[81] S. Fukuda, M. Takeuchi, K. Fujii, R. Kanzaki, T. Takamuku, K. Chiba, H. Yamamoto, Y. Umebayashi, S. Ishiguro, J. Mol. Liquids, 143 (2008) 2-7.

[82] K. Fujii, T. Takamuku, T. Yamaguchi, Y. Umebayashi, S. Ishiguro, Chem. Lett., 38 (2009) 340-341.

[83] Y. Umebayashi, H. Hamano, S. Seki, B. Minofar, K. Fujii, K. Hayamizu, S. Tsuzuki, Y. Kameda, S. Kohara, M. Watanabe, J. Phys. Chem. B, 115 (2011) 12179-12191.

[84] Y. Umebayashi, H. Hamano, S. Tsuzuki, J. N. C. Lopes, A. A. H. Padua, Y. Kameda, S. Kohara, T. Yamaguchi, K. Fujii, S. shiguro, J. Phys. Chem. B 114 (2010) 11715-11724.

[85] K. Ueno, H. Tokuda, M. Watanabe, Phys. Chem. Chem. Phys., 12 (2010) 1649-1658.

[86] S. Tsuzuki, H. Tokuda, K. Hayamizu, M. Watanabe, J. Phys. Chem. B, 109 (2005) 16474-16481.

[87] A. Bondi, J. Phys. Chem., 68 (1964) 441-451.

[88] R. S. Rowland, R. Taylor, J. Phys. Chem., 100 (1996) 7384-7391.

[89] Y. Umebayashi, W. Chung, T. Mitsugi, S. Fukuda, M. Takeuchi, K. Fujii, T. Takamuku, R. Kanzaki, S. Ishiguro, J. Comput. Chem. Jpn., 7 (2008) 125-134.

[90] W. Song, H. Hamano, B. Minofar, R. Kanzaki, K. Fujii, Y. Kameda, S. Kohara, M. Watanabe, S. Ishiguro, Y. Umebayashi, J. Phys. Chem. B, 116 (2012) 2801-2813. 
Table 1 Selected properties, melting point $T_{\mathrm{m}}$, density $\rho$, ionic conductivity $\sigma$ and viscosity h for $\left[\mathrm{C}_{1} \mathrm{mIm}^{+}\right]\left[\mathrm{TFSA}^{-}\right],\left[\mathrm{C}_{1} \mathrm{hIm}^{+}\right]\left[\mathrm{TFSA}^{-}\right]$and $\left[\mathrm{h}_{2} \mathrm{Im}^{+}\right]\left[\mathrm{TFSA}^{-}\right]$.

\begin{tabular}{|c|c|c|c|}
\hline & {$\left[\mathrm{C}_{1} \mathrm{mIm}^{+}\right]\left[\mathrm{TFSA}^{-}\right]$} & {$\left[\mathrm{C}_{1} \mathrm{hIm}^{+}\right]\left[\mathrm{TFSA}^{-}\right]$} & {$\left[\mathrm{h}_{2} \mathrm{Im}^{+}\right]\left[\mathrm{TFSA}^{-}\right]$} \\
\hline$T_{\mathrm{m}} /{ }^{\circ} \mathrm{C}$ & $26^{a}$ & 49 & $73^{b}$ \\
\hline$\rho / \mathrm{g} \mathrm{cm}^{-3}$ & $1.557^{c}$ & $1.614^{c}$ & $1.552^{f}$ \\
\hline$\sigma / \mathrm{mS} \mathrm{cm}^{-1}$ & $11.0^{a, d}$ & $11.9^{e}$ & $24.0^{b, g}$ \\
\hline$\eta / \mathrm{mPa} s$ & $31.0^{a, d}$ & $19.4^{e}$ & - \\
\hline
\end{tabular}

${ }^{a}$ Ref. 22, b Ref. $13,{ }^{c}$ at $25^{\circ} \mathrm{C},{ }^{d}$ at $30{ }^{\circ} \mathrm{C},{ }^{e}$ at $70{ }^{\circ} \mathrm{C},{ }^{f}$ at $115^{\circ} \mathrm{C},{ }^{g}$ at $120{ }^{\circ} \mathrm{C}$. 
Table 2 Partial atomic charges for $\left[\mathrm{C}_{1} \mathrm{mIm}^{+}\right],\left[\mathrm{C}_{1} \mathrm{hIm}{ }^{+}\right]$and $\left[\mathrm{h}_{2} \mathrm{Im}^{+}\right]$.

\begin{tabular}{ccccccc}
\hline & \multicolumn{2}{c}{$\left[\mathrm{C}_{1} \mathrm{mIm}^{+}\right]$} & \multicolumn{2}{c}{$\left[\mathrm{C}_{1} \mathrm{hIm}^{+}\right]$} & \multicolumn{2}{c}{$\left[\mathrm{h}_{2} \mathrm{Im}^{+}\right]$} \\
\hline atom & ab initio & MD & ab initio & MD & ab initio & MD \\
\hline $\mathrm{N}_{\mathrm{A}}$ & 0.153 & 0.15 & 0.187 & 0.15 & & \\
$\mathrm{C}_{\mathrm{R}}$ & -0.097 & -0.11 & -0.009 & 0.00 & 0.057 & 0.04 \\
$\mathrm{C}_{\mathrm{W}}$ & -0.124 & -0.13 & -0.114 & -0.13 & & \\
$\mathrm{~N}_{\mathrm{AH}}$ & & & -0.180 & -0.21 & -0.133 & -0.16 \\
$\mathrm{C}_{\mathrm{WH}}$ & & & -0.042 & -0.03 & -0.043 & -0.03 \\
$\mathrm{C}_{1}$ & -0.17 & -0.17 & -0.247 & -0.17 & & \\
$\mathrm{H}_{\mathrm{CR}}$ & 0.202 & 0.21 & 0.195 & 0.21 & 0.195 & 0.21 \\
$\mathrm{H}_{\mathrm{CW}}$ & 0.203 & 0.21 & 0.196 & 0.21 & 0.196 & 0.21 \\
$\mathrm{H}_{1}$ & 0.136 & 0.13 & 0.150 & 0.13 & & \\
$\mathrm{H}_{\mathrm{NA}}$ & & & 0.365 & 0.37 & 0.353 & 0.355 \\
\hline
\end{tabular}


Table 3 Peak positions and accumulated coordination numbers $n$ evaluated from the center of masses of cation - anion pair correlation functions

\begin{tabular}{cccccccccc}
\hline & \multicolumn{2}{c}{ First peak } & \multicolumn{2}{c}{ Second peak } & \multicolumn{2}{c}{ Third peak } & \multicolumn{2}{c}{ Fourth peak } \\
\hline & position & $n$ & position & $n$ & position & $n$ & position & $n$ \\
& 4.56 & 0.75 & 5.44 & 2.80 & 6.67 & 6.47 & 8.14 & 7.04 \\
{$\left[\mathrm{C}_{1} \mathrm{mIm}^{+}\right]\left[\mathrm{TFSA}^{-}\right]$} & 4.45 & 0.31 & 5.38 & 3.47 & 6.63 & 4.10 & 6.80 & 7.10 \\
$\begin{array}{c}{\left[\mathrm{C}_{1} \mathrm{hIm}^{+}\right]\left[\mathrm{TFSA}^{-}\right]} \\
\text {at 298K }\end{array}$ & & & & & & & & \\
{$\left[\mathrm{C}_{1} \mathrm{hIm}^{+}\right]\left[\mathrm{TFSA}{ }^{-}\right]$} & 4.53 & 0.33 & 5.42 & 3.38 & 6.56 & 4.46 & 7.02 & 7.05 \\
$\begin{array}{c}\text { at 383K } \\
{\left[\mathrm{h}_{2} \mathrm{Im}^{+}\right]\left[\mathrm{TFSA}^{-}\right]}\end{array}$ & 5.08 & 3.06 & 6.28 & 4.51 & 6.70 & 7.14 & & \\
\hline
\end{tabular}


Table 4 Structural parameters, bond length $r$, bond angle $\theta$ and coordination number $n$ for the $\mathrm{NH}^{\cdots} \mathrm{O}$ hydrogen bond and the $\mathrm{C}_{2} \mathrm{H} \cdots \mathrm{O}$ interaction found in MD simulations. .

\begin{tabular}{cccccc}
\hline & \multicolumn{2}{c}{$r / \AA$} & \multicolumn{2}{c}{$\theta /$ deg. } & $n^{a}$ \\
\hline & $\mathrm{NH} \cdots \mathrm{O}$ & $\mathrm{C}_{2} \mathrm{H}^{a} \mathrm{O}$ & $\mathrm{NH} \cdots \mathrm{O}$ & $\mathrm{C}_{2} \mathrm{H} \cdots \mathrm{O}$ & $\mathrm{NH} \cdots \mathrm{O}$ \\
{$\left[\mathrm{C}_{1} \mathrm{mIm}^{+}\right]$} & & 2.58 & & 123 & \\
{$\left[\mathrm{C}_{1} \mathrm{hIm}^{+}\right]$at $298 \mathrm{~K}$} & 1.72 & 2.58 & 166 & 132 & 1.20 \\
{$\left[\mathrm{C}_{1} \mathrm{hIm}^{+}\right]$at $383 \mathrm{~K}$} & 1.76 & 2.58 & 160 & 138 & 1.14 \\
{$\left[\mathrm{~h}_{2} \mathrm{Im}^{+}\right]$} & 1.76 & 2.64 & 160 & 142 & 1.13 \\
\hline
\end{tabular}

${ }^{a} r<2.5 \AA$. 


\section{Figure captions}

Fig. 1 Structures and abbreviations for the cations and the anion of ionic liquids studied in this study.

Fig. 2 X-ray structure factors $S^{\mathrm{X} \text {-ray }}(Q)$ for (a) $\left[\mathrm{C}_{1} \mathrm{mIm}^{+}\right]\left[\mathrm{TFSA}^{-}\right]$(thin black line) and $\left[\mathrm{C}_{1} \mathrm{hIm}^{+}\right]\left[\mathrm{TFSA}^{-}\right]$(gray) at $298 \mathrm{~K}$, (b) $\left[\mathrm{C}_{1} \mathrm{hIm}^{+}\right]\left[\mathrm{TFSA}^{-}\right]$(gray) at $383 \mathrm{~K}$ and $\left[\mathrm{h}_{2} \mathrm{Im}^{+}\right]$ [TFSA ${ }^{-}$] (thick black) at 388K, (c) the corresponding differential radial distribution functions as the form of $r^{2}\left[G^{\mathrm{X} \text {-ray }}(r)-1\right]$ for $\left[\mathrm{C}_{1} \mathrm{mIm}^{+}\right]\left[\mathrm{TFSA}^{-}\right]$(thin black) and $\left[\mathrm{C}_{1} \mathrm{hIm}^{+}\right]\left[\mathrm{TFSA}^{-}\right]$(gray) at $298 \mathrm{~K}$ and (d) $\left[\mathrm{C}_{1} \mathrm{hIm}^{+}\right]\left[\mathrm{TFSA}^{-}\right]$(gray) at $383 \mathrm{~K}$ and $\left[\mathrm{h}_{2} \mathrm{Im}^{+}\right]$ [TFSA ${ }^{-}$] (thick black) at 388K, respectively.

Fig. $3 G_{\text {inter }}(r)$ for (a) $\left[\mathrm{C}_{1} \mathrm{mIm}^{+}\right]\left[\mathrm{TFSA}^{-}\right]$at $298 \mathrm{~K}$, (b) $\left[\mathrm{C}_{1} \mathrm{hIm}^{+}\right]\left[\mathrm{TFSA}^{-}\right]$at $298 \mathrm{~K}$, (c) $\left[\mathrm{h}_{2} \mathrm{Im}^{+}\right]\left[\mathrm{TFSA}^{-}\right]$at $388 \mathrm{~K}$ and (d) $\left[\mathrm{C}_{1} \mathrm{hIm}^{+}\right]\left[\mathrm{TFSA}^{-}\right]$at $383 \mathrm{~K}$. Plots and lines represent experimental and simulated data, respectively.

Fig. 4 Center of masses pair correlation functions for (a) $\left[\mathrm{C}_{1} \mathrm{mIm}^{+}\right]\left[\mathrm{TFSA}^{-}\right]$at $298 \mathrm{~K}$, (b) $\left[\mathrm{C}_{1} \mathrm{hIm}^{+}\right]\left[\mathrm{TFSA}^{-}\right]$at $298 \mathrm{~K}$, (c) $\left[\mathrm{h}_{2} \mathrm{Im}^{+}\right]\left[\mathrm{TFSA}^{-}\right]$at $388 \mathrm{~K}$ and (d) $\left[\mathrm{C}_{1} \mathrm{hIm}^{+}\right]\left[\mathrm{TFSA}^{-}\right]$at 383K. Black, red and blue lines represent for the cation - anion, the cation - cation and the anion - anion correlation, respectively.

Fig. 5 Spatial distribution functions for (a) $\left[\mathrm{C}_{1} \mathrm{mIm}^{+}\right]\left[\mathrm{TFSA}^{-}\right]$at $298 \mathrm{~K}$, (b) $\left[\mathrm{C}_{1} \mathrm{hIm}^{+}\right]\left[\mathrm{TFSA}^{-}\right]$at $298 \mathrm{~K}$, (c) $\left[\mathrm{h}_{2} \mathrm{Im}^{+}\right]\left[\mathrm{TFSA}^{-}\right]$at $388 \mathrm{~K}$ and (d) $\left[\mathrm{C}_{1} \mathrm{hIm}^{+}\right]\left[\mathrm{TFSA}^{-}\right]$at 383K. Blue and green clouds display the closest cation-anion (4-folds number density relative to the bulk) and the second layer cation-cation (1.8-folds) distributions

Fig. 6 Spatial distribution functions for the $\mathrm{O}$ (5-folds) and the $\mathrm{F}$ (2.5^folds) atoms in the $\mathrm{TFSA}^{-}$around the respective cation; (a) $\left[\mathrm{C}_{1} \mathrm{mIm}^{+}\right]\left[\mathrm{TFSA}^{-}\right]$at $298 \mathrm{~K}$, (b) $\left[\mathrm{C}_{1} \mathrm{hIm}^{+}\right]\left[\mathrm{TFSA}^{-}\right]$at $298 \mathrm{~K}$, (c) $\left[\mathrm{C}_{1} \mathrm{hIm}^{+}\right]\left[\mathrm{TFSA}^{-}\right]$at $383 \mathrm{~K}$ and (d) $\left[\mathrm{h}_{2} \mathrm{Im}^{+}\right]\left[\mathrm{TFSA}^{-}\right]$at 388K. Electrostatic potentials for (e) $\left[\mathrm{C}_{1} \mathrm{mIm}^{+}\right]$, (f) $\left[\mathrm{C}_{1} \mathrm{hIm}{ }^{+}\right]$and (g) $\left[\mathrm{h}_{2} \mathrm{Im}^{+}\right]$are also shown for comparison.

Fig. 7 Typical partial atom-atom pair correlation functions $g(r)$ for (a) $\left[\mathrm{C}_{1} \mathrm{mIm}^{+}\right]\left[\mathrm{TFSA}^{-}\right]$(black), and $\left[\mathrm{C}_{1} \mathrm{hIm}^{+}\right]\left[\mathrm{TFSA}^{-}\right]$(gray) at $298 \mathrm{~K}$ and (b) $\left[\mathrm{C}_{1} \mathrm{hIm}^{+}\right]\left[\mathrm{TFSA}^{-}\right]$(gray) at $383 \mathrm{~K}$ and $\left[\mathrm{h}_{2} \mathrm{Im}\right]\left[\mathrm{TFSA}^{-}\right]$(black) at $388 \mathrm{~K}$. 
Fig. 1 Watanabe et al.
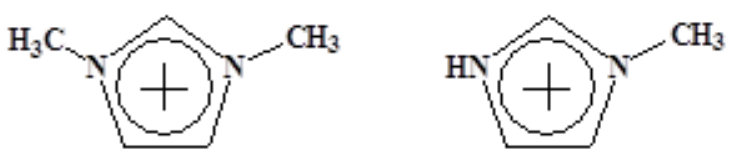

$N, N$-dimethylimidazolium $N$-methylimidazolium

$\mathrm{C}_{1} \mathrm{mIm}^{+}$
$\mathrm{C}_{\mathbf{l}} \mathrm{hIm}^{+}$

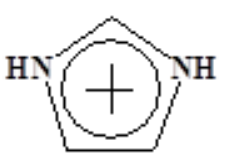

Imidazolium

$\mathbf{h}_{2} \operatorname{Im}^{+}$<smiles>O=S(=O)(O)NS(=O)(=O)C(F)(F)C(F)(F)F</smiles>

Bis(trifluoromethane -sulfonyl)Amide TFSA $^{-}$ 
Fig. 2 Watanabe et al.
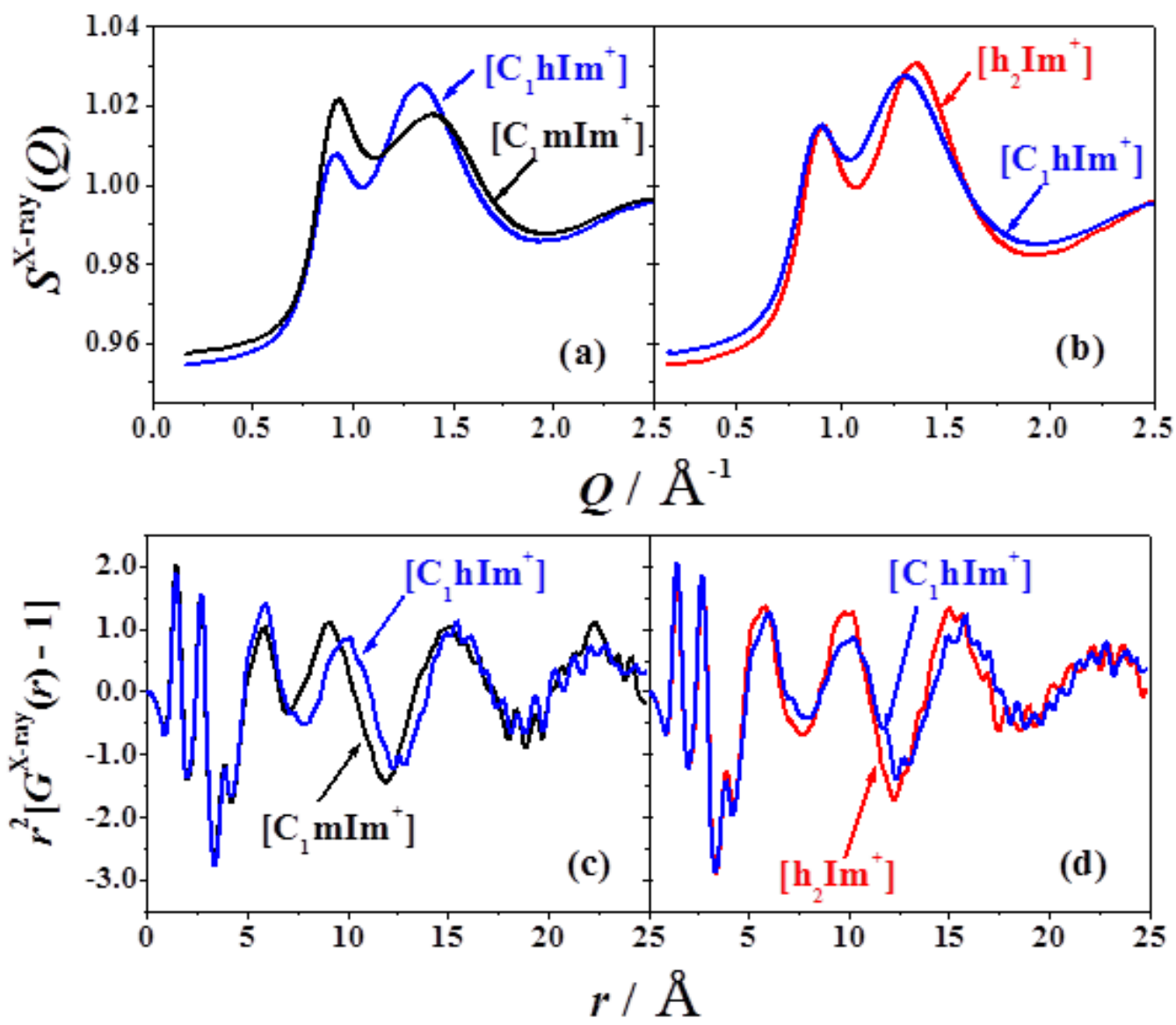
Fig. 3 Watanabe et al.

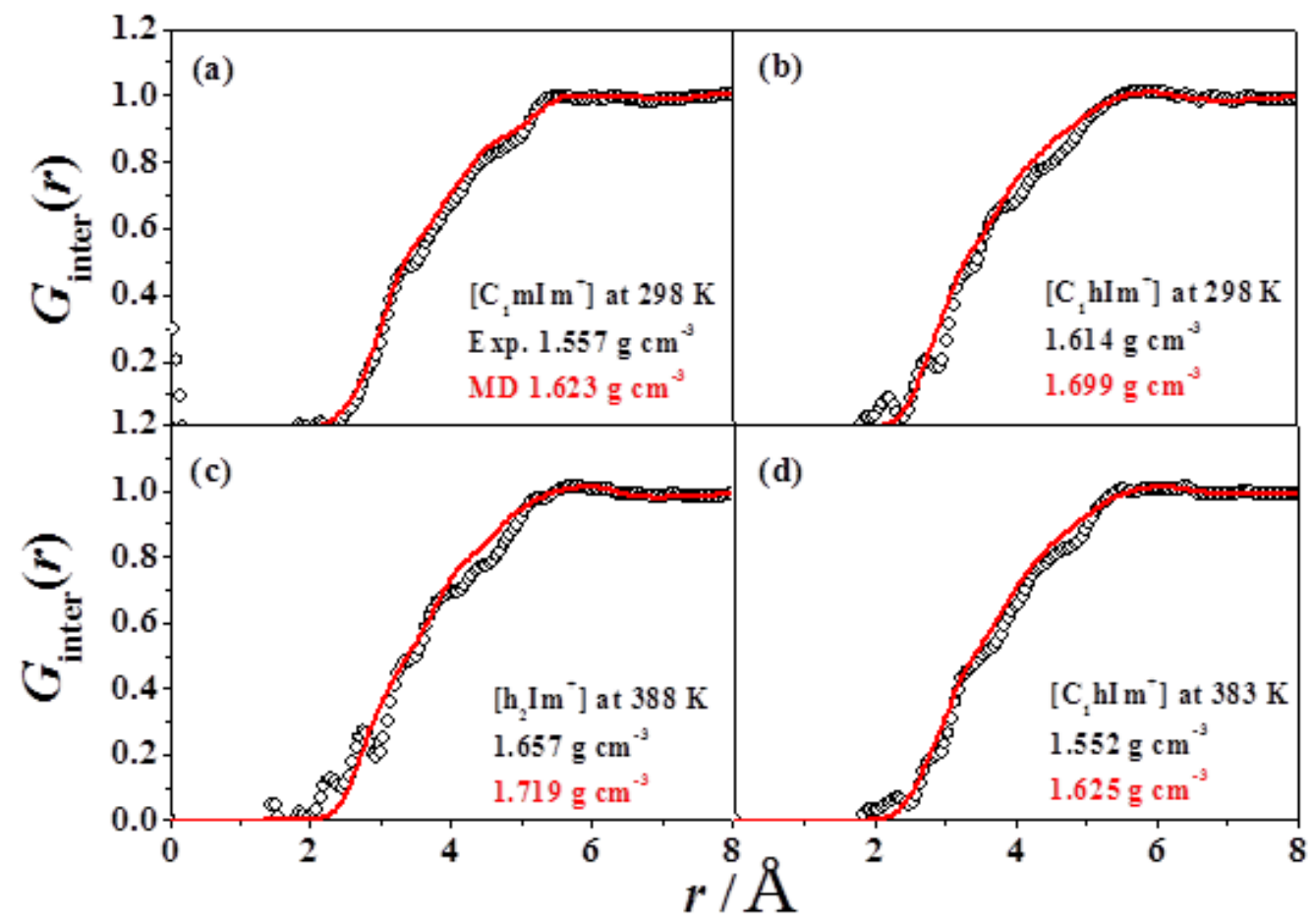


Fig. 4 Watanabe et al.

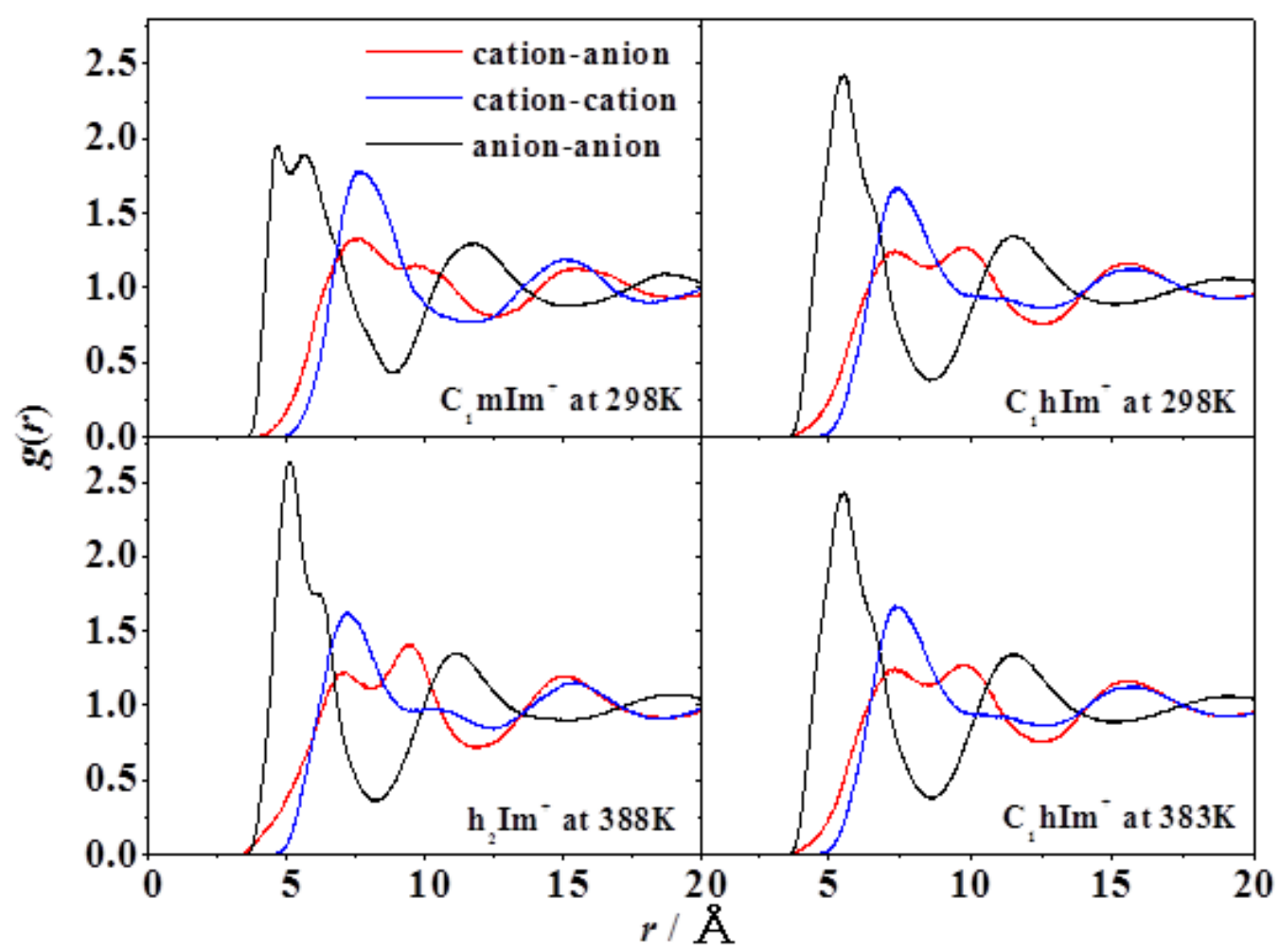


Fig. 5 Watanabe et al.

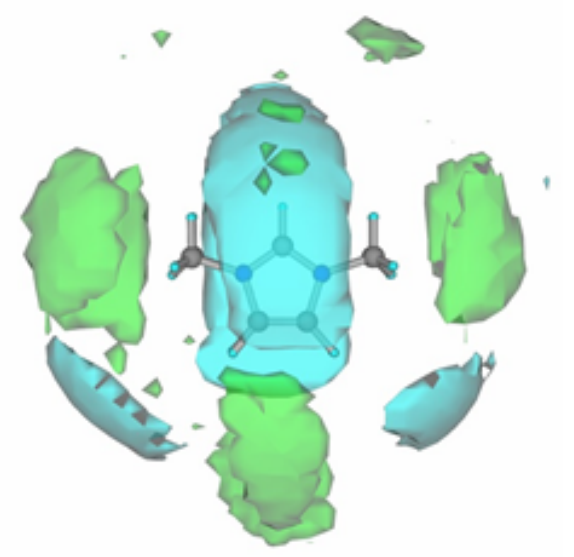

$\left[\mathrm{C}_{1} \mathrm{mIm}^{+}\right]$at $298 \mathrm{~K}$
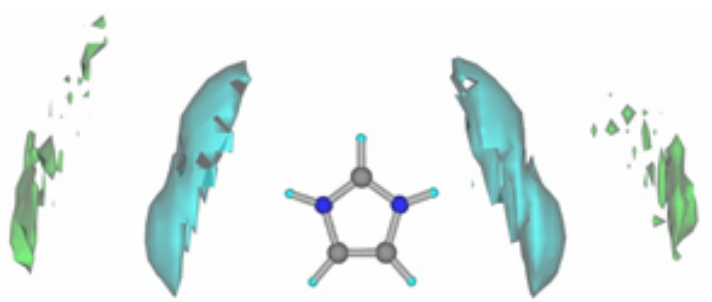

$\left[\mathrm{h}_{2} \mathrm{Im}^{+}\right]$at $388 \mathrm{~K}$

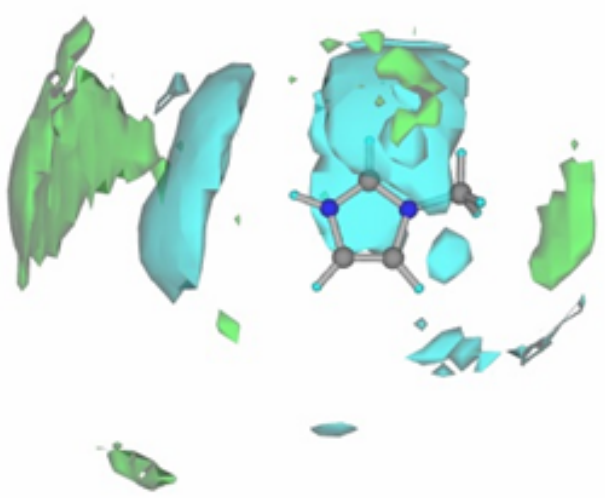

$\left[\mathrm{C}_{1} \mathrm{hLm}^{+}\right]$at $298 \mathrm{~K}$
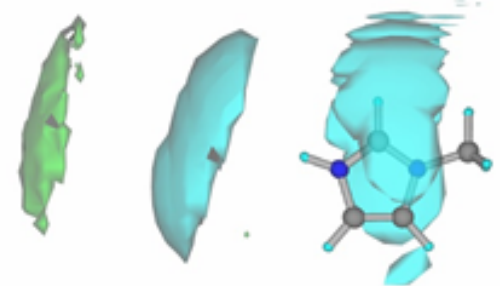

$\left[\mathrm{C}_{1} \mathrm{hIm}^{+}\right]$at $383 \mathrm{~K}$ 
Fig. 6 Watanabe et al.

(a) $\left[\mathrm{C}_{1} \mathrm{mIm}^{+}\right]$at $298 \mathrm{~K}$
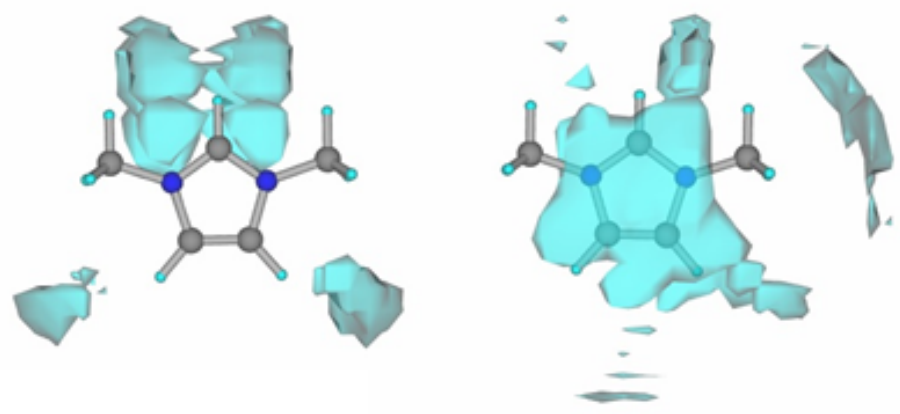

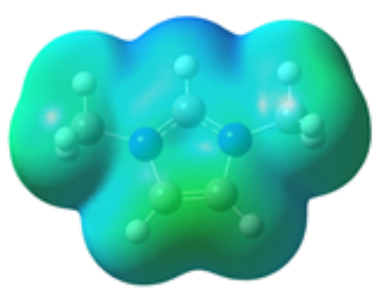

(e)

(b) $\left[\mathrm{C}_{1} \mathrm{hIm}^{+}\right]$at $298 \mathrm{~K}$
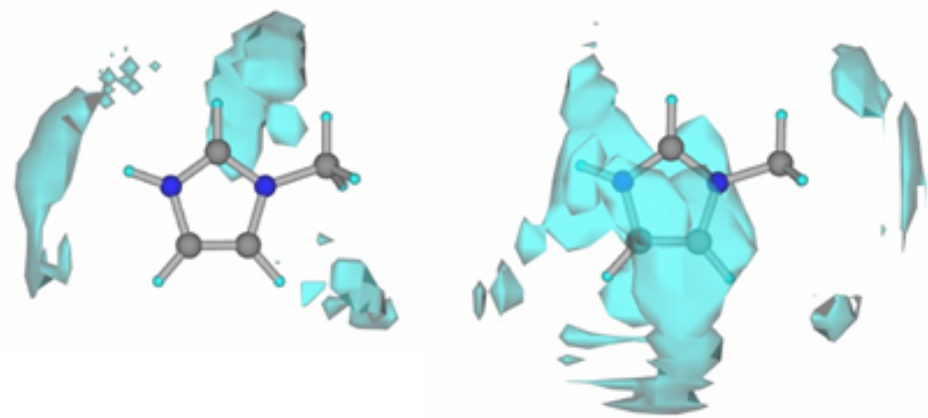

(c) $\left[\mathrm{C}_{1} \mathrm{hIm}^{+}\right]$at $383 \mathrm{~K}$
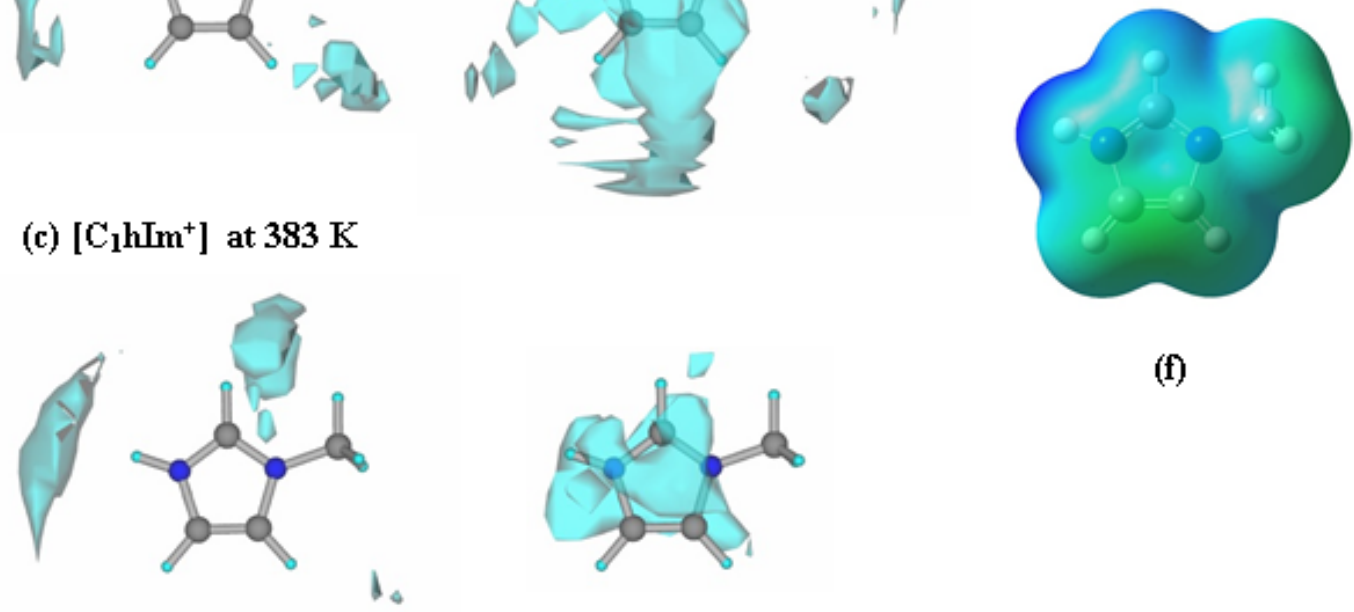

(f)

(d) $\left[\mathrm{h}_{2} \mathrm{Im}^{+}\right]$at $388 \mathrm{~K}$

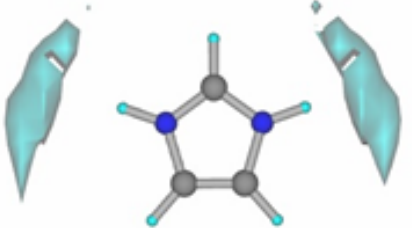

SDF of $O$ atom

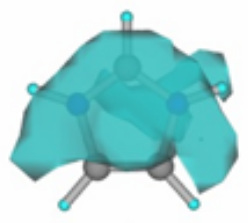

SDF of F atom

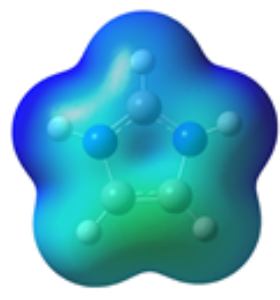

(g) 
Fig. 7 Watanabe et al.

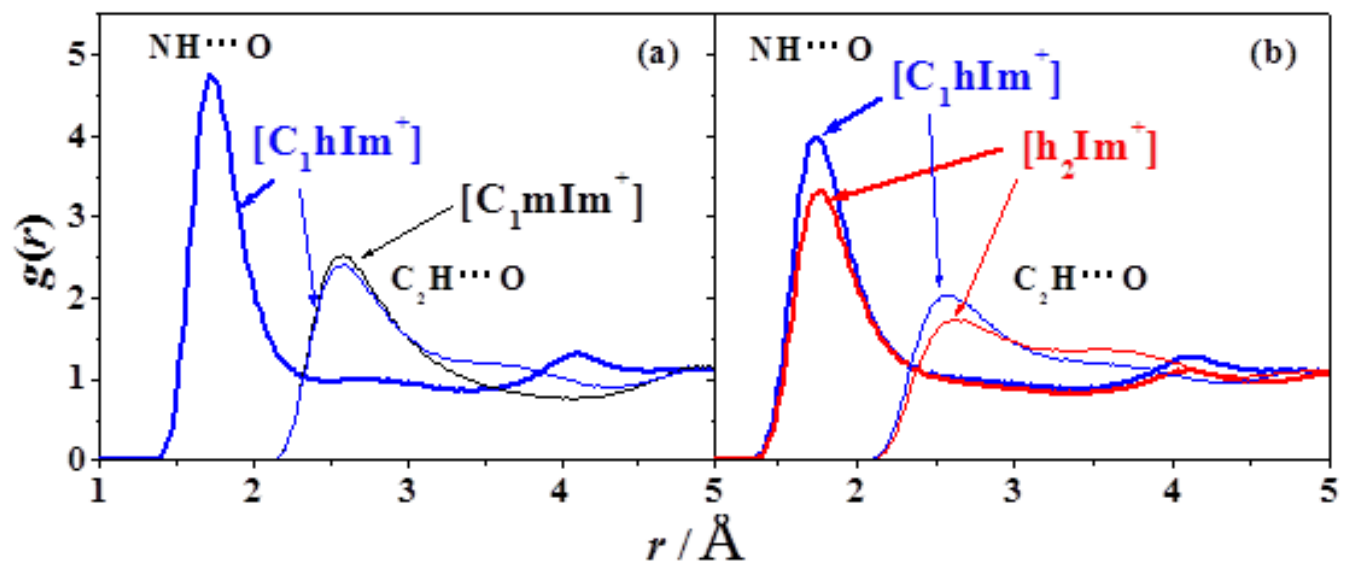

